\title{
LA UTILIDAD DEL REFERÉNDUM COMO ACICATE $Y$ CONTRAPESO EN LAS DEMOCRACIAS REPRESENTATIVAS ${ }^{1}$
}

\author{
The usefulness of referendums in enhancing \\ and counterbalancing representative democracies
}

\author{
CARLOS GARRIDO LÓPEZ \\ Universidad de Zaragoza \\ cgarrido@unizar.es \\ Cómo citar/Citation \\ Garrido López, C. (2018). \\ La utilidad del referéndum como acicate y \\ contrapeso en las democracias representativas. \\ Revista de Estudios Políticos, 181, 135-165. \\ doi: https://doi.org/10.18042/cepc/rep.181.05
}

\section{Resumen}

El uso del referéndum ha crecido exponencialmente en los últimos años en el derecho comparado y se ha generalizado en todos los niveles de gobierno. Y no solo donde ya estaba normalizado como cauce habitual de participación política, sino también allí donde había sido usado exclusivamente para consultar sobre cuestiones de gran trascendencia. Ello ha evidenciado que el referéndum puede complementar la democracia representativa, estimulando su representatividad y actuando de contrapeso. Pero también ha mostrado que no todo referéndum profundiza la democracia; que lo consiga o no depende de sus garantías. En este trabajo se analizan la funcionalidad de varias modalidades de referéndum y las principales garantías que cabe implementar para compatibilizarlas con la democracia representativa, especialmente la ampliación de los sujetos legitimados para instar su convocatoria, la exclusión de materias objeto de consulta y las exigencias de quorum y de mayorías reforzadas para conferir validez al resultado.

1 Este trabajo se enmarca en el proyecto de investigación (DER2016-75406-R) sobre «Modelos de derecho comparado para una nueva regulación del referéndum y la iniciativa popular en España», financiado por el MINECO (Investigadores principales: Eva Sáenz Royo y Carlos Garrido López). 


\title{
Palabras clave
}

Democracia directa; referéndums; garantías.

\begin{abstract}
The use of referendums has grown exponentially in recent years in comparative law and has become widespread at all levels of government, not only where it was already normalised as a usual channel for political participation, but also where it had previously solely been used to answer questions of great importance. This has shown that referendums can complement representative democracy, by enhancing its representativeness and acting as a counterbalance. However, it has also shown that not all referendums enrich democracy: it depends upon who is asking, what they are asking about and under what conditions the campaign is debated. In short, it depends on its guarantees. In this paper I analyse the functionality of several types of referendum and the principal guarantees that can be implemented to make them compatible with representative democracy, especially the expansion of people with the legal authority to lobby for their calling, the exclusion of certain issues in referendums and the requirements for a quorum or for a qualified majority for the result to be recognised as valid.
\end{abstract}

\section{Keywords}

Direct democracy; referendums; guarantees. 


\section{SUMARIO}

I. LA EXTENSIÓN DEL REFERÉNDUM EN LAS DEMOCRACIAS REPRESENTATIVAS. II. MODALIDADES DE REFERÉNDUM QUE COMPLEMENTAN LA DEMOCRACIA REPRESENTATIVA: 1. Los referéndums para legitimar grandes decisiones políticas: los referéndums de reforma constitucional y los referéndums consultivos sobre cuestiones de especial trascendencia. 2. Los referéndums propositivos de normas, los legislativos de ratificación y los abrogatorios de leyes en vigor. III. LAS PRINClPALES GARANTÍAS NORMATIVAS DE LOS REFERÉNDUMS: SU IMPLEMENTACIÓN EN EL DERECHO COMPARADO: 1. La pluralidad de sujetos legitimados para instar su convocatoria. En especial, la iniciativa popular de referéndum. 2. Las cuestiones excluidas de la iniciativa de referéndum y el control de admisibilidad. 3. Participación popular mínima y exigencia de mayorías reforzadas. IV. CONSIDERACIONES FINALES. BibLIOgRAFía.

\section{LA EXTENSIÓN DEL REFERÉNDUM EN LAS DEMOCRACIAS REPRESENTATIVAS}

La representación política es un elemento constitutivo de la democracia, pero ello no excluye, como subrayó Böckenförde (2000: 143-144), «que el poder de decisión y dirección representativo se pueda corregir y contrapesar democráticamente [...] mediante la decisión directa sobre ciertos asuntos por el pueblo mismo». La democracia directa "desempeña así un papel en la organización democrática del poder del Estado: no como un principio fundamental de su construcción, sino como un elemento corrector o de contrapeso. Es en este sentido como pueden y como deben incorporarse estos componentes en la organización constitucional democrática».

Respondiendo a esta lógica, la mayoría de los ordenamientos constitucionales ha optado por incorporar en su estructura institucional la figura del referéndum. En algunos, su regulación es muy restrictiva y su utilización resulta excepcional, como ocurre en el ordenamiento español. En otros, en cambio, el uso del referéndum ha crecido exponencialmente en los últimos años y se ha generalizado en todos los niveles de gobierno. Y no solo donde ya estaba normalizado como cauce habitual de participación política, sino también allí donde 
había sido usado exclusivamente para consultar sobre cuestiones políticas de gran trascendencia ${ }^{2}$.

En Irlanda, la participación directa en referéndum constituye un rasgo característico de su sistema político, habiéndose celebrado en las últimas décadas 39 referéndums de carácter constitucional y sobre tratados europeos. En Italia, los referéndums están previstos constitucional y estatutariamente en los tres niveles de gobierno, destacando en la práctica el referéndum legislativo abrogatorio de iniciativa popular, modalidad que ha sido usada desde 1974 hasta en 67 ocasiones en el ámbito nacional. En Suiza, el referéndum se practicó inicialmente en los ámbitos local y cantonal, extendiéndose después a nivel federal, especialmente tras la constitucionalización de los referéndums legislativos abrogatorios a iniciativa popular y el reconocimiento de la iniciativa popular de referéndum para las revisiones parciales de la Constitución. El empleo de ambas modalidades ha sido una constante en Suiza y su uso se ha incrementado desde 1980, habiéndose celebrado cientos de referéndums constitucionales y legislativos a nivel federal. En Reino Unido, pese al respeto por el dogma de la soberanía parlamentaria, el referéndum también ha adquirido protagonismo en los últimos años para consultar sobre decisiones políticas de especial trascendencia, como la permanencia o salida de la Unión Europea, el sistema electoral e importantes cuestiones territoriales. Y su celebración cuenta con una rigurosa regulación de garantías contenida en la Political Parties, Elections and Referendums Act 2000. En Alemania, la Grundgesetz solo establece el referéndum nacional para una eventual reorganización del territorio federal (art. 29). Las constituciones de los Länder contienen, en cambio, una generosa regulación de la democracia directa y a su amparo se han celebrado en los últimos ańos más de 220 referendos estatales sobre cuestiones legislativas y constitucionales. En EE. UU., el referéndum no está regulado a nivel federal, pero todos los estados prevén el referéndum a iniciativa de los gobiernos y en veinticuatro estados existe, además, el referéndum legislativo y/o constitucional a iniciativa popular de una fracción de electores, que pueden determinar de este modo la agenda política y plantear reformas que posiblemente no prosperarían de depender del impulso de los partidos políticos. En las dos últimas décadas, también en América Latina se ha generalizado la regulación del referéndum, incrementándose sus garantías y extendiéndose su uso, especialmente en países como Uruguay, Ecuador, Colombia y Costa Rica, cuyas

2 Una relación de los referendos celebrados por países en los últimos años puede verse en la web del Centre for Research on Direct Democracy de la Universidad de Zúrich: http://bit.ly/2LSAmgK. Sobre la generalización del referéndum, asimismo, Kaufmann y Waters (2004) y Qvortrup (2002). 
constituciones reconocen la posibilidad de convocar referéndums constitucionales y legislativos a iniciativa popular ${ }^{3}$.

En ninguno de los países citados la democracia ha sucumbido a la demagogia por la práctica de la participación directa. El incremento en el uso del referéndum no ha menoscabado ni la posición constitucional de los parlamentos ni el poder de representación del pueblo que dichos órganos tienen asignados y que siguen detentando con la sola reserva del eventual ejercicio directo del derecho de participación a través de referéndum. Dicho ejercicio es compatible con el parlamentarismo porque, como señaló Carré de Malberg (2014: 299), "desde el momento [...] en que el poder del Estado y de sus órganos se funda sobre la idea de soberanía de la voluntad general, se convierte en manifiestamente imposible negar la capacidad de deliberar e incluso de decidir a aquellos de los que la voluntad general toma su origen y su consistencia, esto es, a los ciudadanos que se reúnen a este efecto en un colegio único e indivisible».

Pese a las tesis sostenidas por cierta doctrina (Nuss, 2000: 1448-1456; Haskell, 2001: 11-24; Sartori, 2007: 125-129), la democracia directa no cuestiona la democracia representativa, porque ambas pueden integrarse recíprocamente ${ }^{4}$ «[...] ni la iniciativa popular, ni el referéndum —afirmó De Vega (1985: 122) — pretenden suplantar los mecanismos y el ejercicio normal de los poderes constituidos. Su actuación no implica el asalto al Estado constitucional, sino que, al contrario, significa una complementación del sistema de los checks and balances, de los frenos y contrapesos que más genuinamente lo definen y caracterizan». Regulado con las garantías precisas, el referéndum amplía las posibilidades de participación, implica a los ciudadanos en el proceso de adopción de las decisiones colectivas y refuerza la legitimidad del sistema político. El referéndum puede ser, por ello, un instrumento eficaz de integración política. Y puede operar como acreditado complemento de la democracia representativa, posibilitando la participación popular directa en el proceso constituyente y en los procedimientos legislativos o gubernamentales de adopción de decisiones colectivas.

3 La regulación constitucional de los mecanismos de democracia directa en América Latina ha contribuido, precisamente, al asentamiento de los sistemas democráticos, permitiendo acotar o disminuir las consultas ad hoc de signo plebiscitario, "verdadero germen de liderazgos populistas y autoritarios en la región» (Soto, 2013: 319-320).

4 La democracia, ha señalado Bobbio (1986: 60-61), "puede abarcar a las dos, a cada una de acuerdo con las diversas situaciones y a diferentes necesidades, porque son, en cuanto adaptables a diversas situaciones y a diferentes necesidades, perfectamente compatibles entre ellas». 


\section{MODALIDADES DE REFERÉNDUM QUE COMPLEMENTAN LA DEMOCRACIA REPRESENTATIVA}

\section{LOS REFERÉNDUMS PARA LEGITIMAR GRANDES DECISIONES POLÍTICAS: LOS REFERÉNDUMS DE REFORMA CONSTITUCIONAL Y LOS REFERÉNDUMS CONSULTIVOS SOBRE CUESTIONES DE ESPECIAL TRASCENDENCIA}

El referéndum es un recurso institucional que puede utilizarse para ratificar o legitimar las grandes decisiones políticas, como los supuestos de reforma constitucional o la delegación de poderes a autoridades internacionales, y también puede servir para descargar de responsabilidad al Parlamento en aquellas decisiones críticas, denominadas por Schneider (1991: 260) «decisiones de nuevo tipo», cuyo alcance e irreversibilidad comprometen a las generaciones futuras.

Conciliando, en expresión de Santamaría (1972: 755), «la noción democrática de la participación directa con la noción conservadora de la rigidez constitucional», varios Estados prevén con carácter preceptivo y vinculante la celebración de referéndums de reforma constitucional. Suiza introdujo en 1848 el referéndum preceptivo para las reformas constitucionales y reconoció la iniciativa de reforma a un número de ciudadanos. En 1891, se añadió la iniciativa popular para las revisiones parciales de la Constitución, que se someten a referéndum después de que la Asamblea Federal haya mostrado su aceptación o rechazo, en ocasiones junto con contrapropuestas o contraproyectos elaborados por la propia Asamblea que incorporan parcialmente algunas demandas de los promotores de las iniciativas. Y en 1921, se constitucionalizó el referéndum facultativo sobre tratados internacionales de duración indeterminada, cuyo ámbito fue ampliado en 1977 a otros tratados internacionales. Todas estas modalidades, reguladas en los arts. 138 a 141 de la Constitución, han sido profusamente utilizadas, especialmente en las últimas décadas ${ }^{5}$. En Irlanda, la convocatoria de referéndum es preceptiva para cualquier reforma constitucional (art. 46 de la Constitución) y, desde la decisión de la Corte Suprema en el caso Crotty v. AnTaoiseach adoptada en 1987, también lo es para la ratificación de reformas a los tratados de la UE y de nuevos tratados al amparo de una interpretación estricta del art. 29.4.3 de la Constitución ${ }^{6}$. En

5 Los referendos suizos, su objeto y sus resultados pueden verse en la web de la Cancelleria Federale: http://bit.ly/2vp4HJh. En la doctrina, Kriesi y Trechsel, 1996: 185-208, y Serdült, 2014: 43-64.

6 Sobre el referéndum de reforma constitucional y sobre tratados internacionales en Irlanda, Barret (2014: 93-127). 
Dinamarca también es preceptiva la ratificación popular en casos de delegación de poderes a autoridades internacionales y para la reforma constitucional (arts. 20.2 y 88 de la Constitución, respectivamente). En Alemania, la totalidad de los Länder prevé la celebración de referéndums para la reforma de sus constituciones, que pueden impulsar un porcentaje del cuerpo electoral de cada Land . En el continente americano, todas las constituciones estatales en EE. UU., salvo la de Delaware, exigen referéndum para proceder a su reforma (Donovan, 2014: 122-153); y lo mismo han hecho en los últimos años nueve constituciones latinoamericanas, la mayoría de las cuales (concretamente las de Uruguay, Colombia, Costa Rica, Ecuador, Bolivia, Perú y Venezuela) ha previsto su convocatoria a iniciativa popular (Soto, 2013: 326-333).

Otros Estados prevén genéricamente el referéndum sobre cuestiones de trascendencia nacional, expresión bajo la que los ciudadanos pueden ser convocados para decidir sobre reformas constitucionales, delegación de poderes a entidades supranacionales o decisiones de alcance de las anteriormente citadas por Schneider. En Reino Unido, los referéndums celebrados hasta el momento se enmarcan claramente en esta categoría, aunque sin previsión expresa. Según el informe de la Cámara de los Lores de 2010, los referéndums son apropiados para resolver «cuestiones constitucionales fundamentales», como el cambio del sistema electoral de la Cámara de los Comunes, la salida de la UE o la secesión de alguna nación de Reino Unido, pero necesariamente tienen naturaleza ad hoc y consultiva, porque los supuestos de referéndum no están tasados y se mantiene el principio de soberanía parlamentaria ${ }^{8}$. En Portugal, sí está previsto expresamente el referéndum sobre "cuestiones de relevante interés nacional» que deban ser formalizadas mediante la aprobación de un convenio internacional o un acto legislativo, otorgando la iniciativa a la Asamblea de la República y al Gobierno (art. 115.3 de la Constitución). Hungría regula el referéndum sobre «cuestiones políticas fundamentales» en la Ley III de 1998 sobre el referéndum nacional y la iniciativa popular, y otorga la iniciativa a 200000 ciudadanos. En Polonia, la iniciativa para estos referéndums se atribuye a la Cámara Baja (art. 125 de la Constitución) y, al amparo de la ley de referéndum de 14 de marzo de 2003, a un número no inferior a 500000 ciudadanos. Y también están previstos constitucionalmente los referéndums sobre materias de especial trascendencia en varios países latinoamericanos, pudiendo ser convocados a iniciativa del presidente de la República (Colombia, Ecuador), a

7 Sobre los referéndums en Dinamarca y Alemania, Svensson (1996: 33-51) y Weber (1985: 178-184), respectivamente.

8 House of Lords Select Committee on the Constitution, 2010. Disponible en http:// bit.ly/2vmqIbW. 
iniciativa de la Asamblea o del presidente (Guatemala) o a iniciativa del presidente, por acuerdo de la Asamblea o a solicitud de un $10 \%$ de los electores inscritos en el Registro Civil y Electoral (Venezuela).

\section{LOS REFERÉNDUMS PROPOSITIVOS DE NORMAS, LOS LEGISLATIVOS DE RATIFICACIÓN Y LOS ABROGATORIOS DE LEYES EN VIGOR}

Además de servir para adoptar o ratificar grandes decisiones institucionales, el referéndum puede ser usado como mecanismo de estímulo y de control de la acción legislativa del Parlamento. En este ámbito, el referéndum puede contribuir a ajustar las decisiones legislativas a las demandas de los ciudadanos y operar como instrumento de veto - $\mathrm{o}$ de refuerzo de otros actores de veto- del predominio parlamentario a modo de eficaz contrapeso del entramado institucional (Luciani, 2008: 9-12; Penadés, 2016: 230-231). El referéndum puede ser útil, por tanto, en una doble perspectiva: una potencialmente positiva, encaminada a dinamizar la relación representativa, enfrentar la pasividad de los legisladores hacia materias concretas y, en su caso, favorecer el desbloqueo entre órganos que están llamados a conformar la voluntad colectiva, y otra de carácter negativo, consistente en controlar y compensar los procesos parlamentarios por los que habitualmente discurre la formación de la voluntad general (García, 2012: 16). Con objeto de poder desempeñar estas finalidades, el derecho comparado prevé el referéndum propositivo sobre propuestas normativas surgidas de la sociedad civil, el referéndum para ratificar leyes aprobadas en sede parlamentaria y aún no sancionadas y el referéndum legislativo abrogatorio para, en su caso, derogar leyes en vigor.

Con funcionalidad positiva, la experiencia comparada avala el referéndum propositivo de normas a iniciativa de un número de ciudadanos, a quienes se reconoce la facultad de presentar una propuesta legislativa o constitucional para que sea votada directamente por el cuerpo electoral o para que se debata en el Parlamento y, en el supuesto de ser rechazada, sea sometida a referéndum. La iniciativa legislativa ciudadana permite plantear la regulación legislativa de cuestiones sobre las que los representantes se desentienden y lograr su aprobación. Por su parte, la iniciativa sobre materias constitucionales posibilita a los ciudadanos proponer directamente enmiendas a la Constitución, sin intermediación de sus representantes, cuya resistencia o pasividad la ciudadanía puede así sortear. Ambos modelos, que permiten a los ciudadanos reaccionar ante la inactividad parlamentaria, están previstos a iniciativa de un porcentaje variable del cuerpo electoral en la totalidad de los Länder alemanes y también en veinticuatro estados de EE. UU., donde, en unos casos, las propuestas válidamente suscritas se someten directamente a votación, y, en 
otros, el cuerpo electoral solo vota si las iniciativas no son asumidas por las legislaturas en un plazo determinado.

En Suiza, solo está prevista con perfil propositivo la iniciativa popular de revisión constitucional. El art. 138 de la Constitución otorga a 100000 electores la facultad de proponer su revisión total, iniciativa que se somete directamente a referéndum. El art. 139 de la Constitución faculta al mismo número de electores para proponer revisiones constitucionales parciales, que pueden presentarse ante la Asamblea Federal integralmente redactadas o en forma de proposiciones generales. En ambos supuestos la Asamblea Federal ha de pronunciarse mostrando su aceptación o rechazo. Si la Asamblea Federal comparte las iniciativas populares concebidas en términos generales, debe desarrollarlas antes de la convocatoria del referéndum, sometiéndose el texto resultante al escrutinio popular. Si las rechaza, lo que se somete a referéndum son las iniciativas genéricas de revisión y, de ser aprobadas por el electorado, la Asamblea queda obligada a desarrollarlas. En el caso de las iniciativas populares íntegramente redactadas, la Asamblea Federal debe hacer pública su posición y, simultáneamente, puede elaborar un contraproyecto, que será sometido a referéndum junto con el texto de la iniciativa popular. Al carecer de límites materiales precisos, esta iniciativa de revisiones parciales de la Constitución se ha usado para canalizar la regulación de propuestas normativas que poco tienen que ver con el contenido tradicional de las normas constitucionales y que deberían haberse formalizado en leyes o, incluso, en reglamentos federales. Ello, unido a la ausencia de otra vía para plantear esas propuestas, ha determinado un uso generalizado de esta modalidad como trasunto de referéndum legislativo, habiéndose celebrado más de 190 referéndums de este tipo desde 1874, año en el cual la segunda Constitución federal entró en vigor?

Francia no prevé el referéndum propositivo de revisión constitucional, pero sí el propositivo de leyes. Se introdujo en 2008 y su iniciativa debe partir de una quinta parte de los miembros de la Asamblea Nacional, apoyada por una décima parte del cuerpo electoral, debiendo celebrarse si la propuesta no

9 En 2003 se introdujo, con similar diseño, en el art. 139a de la Constitución federal, la iniciativa popular general, mediante la que un mínimo de 100000 electores podían proponer a la Asamblea en términos generales la adopción, modificación o abrogación de disposiciones constitucionales o legislativas para que esta, de aceptar, las articulara posteriormente. El referéndum debía celebrarse en todo caso, tanto si la Asamblea rechazaba la iniciativa general como si la asumía y articulaba, votándose en la segunda hipótesis las modificaciones redactadas por la Asamblea en desarrollo de la iniciativa y el contraproyecto alternativo que hubiera podido elaborar. Esta modalidad de iniciativa popular no fue utilizada, siendo abrogada en referéndum el 27 de septiembre de 2009. Sobre las razones de la abrogación, Cuesta, 2008: 244-245. 
es examinada por la Cámara en el plazo fijado (art. 11 de la Constitución ${ }^{10}$ ). En Italia, el referéndum propositivo de leyes está reconocido en algunos estatutos regionales. La Constitución no lo regula en el ámbito nacional, pero el referéndum legislativo abrogatorio previsto en el art. 75 CI tiene alcance materialmente propositivo en no pocas ocasiones, porque sus promotores, mediante una cuidadosa selección de las partes de las leyes que se pretenden derogar, pueden innovar el ordenamiento generando realmente nuevas normas y transformando al cuerpo electoral en un genuino legislador alternativo (Rolla, 2017: 229-231; Olivetti, 2007: 159; Sáiz, 1992: 197-198).

Los referéndums sobre leyes votadas y aún no sancionadas y los abrogatorios sobre leyes en vigor también están extendidos en derecho comparado y su función correctora y de contrapeso de la actividad parlamentaria resulta de primer orden, en la medida en que posibilitan el ejercicio de una suerte de «facultad de veto» del cuerpo electoral sobre la actividad legislativa.

La primera modalidad, consistente en la ratificación o suspensión legislativa, puede celebrarse en los Länder alemanes a petición de un porcentaje de inscritos en el censo del Land correspondiente; en Irlanda se convoca a iniciativa conjunta de la mayoría del Senado y de un tercio de los miembros de la Cámara de Representantes (art. 27 de la Constitución); en Austria, la convocatoria procede si lo pide la mayoría de miembros del Consejo Nacional (art. 43 de la Ley Constitucional Federal); en Dinamarca, se activa a propuesta de un tercio del Parlamento (art. 42.1 de la Constitución); en Francia, a propuesta del Gobierno o de forma conjunta por ambas Cámaras (art. 11 de la Constitución); en Letonia, a solicitud de un $10 \%$ de los inscritos en el censo si la ley ha sido suspendida por el presidente de la República (art. 1.3 Law on National Referendums Initiation of Laws and European Citizens Initiative, 1994), y en Eslovenia, si así lo solicitan 40000 ciudadanos (art. 90 de la Constitución).

La segunda modalidad, en la que una ley en vigor puede ser abrogada total o parcialmente mediante referéndum, puede utilizarse en la mayoría de estados de EE. UU. a iniciativa de los Gobiernos y a iniciativa popular. También está regulada en varios países latinoamericanos. En Uruguay, el referéndum abrogatorio se convoca a petición de un $25 \%$ del cuerpo electoral, formulada dentro del primer año a partir de la promulgación de la ley (art. 79 de la Constitución); en Venezuela, a iniciativa del presidente de la República o de un $10 \%$ por ciento de los electores (art. 74 de la Constitución); en Colombia, a iniciativa de un $10 \%$ del censo (art. 170 de la Constitución), y

10 Sobre la introducción de esta modalidad en Francia, Pérez Sola (2008: 131-146), y muy críticamente, Requejo (2013: 204-215). 
en Ecuador y Costa Rica, a iniciativa de un 5\% en ambos casos (arts. 104 y 105 de sus respectivas constituciones). En Europa, el referéndum abrogatorio está previsto en Dinamarca a petición de un tercio de los miembros del Folketing (art. 42.7 de la Constitución) y en Francia, donde, desde 2008, una quinta parte de los miembros de la Asamblea Nacional, apoyada por una décima parte de los electores inscritos en el censo, puede solicitar la celebración de un referéndum abrogatorio de leyes con una vigencia superior a un ańo. Pero es especialmente en Suiza e Italia donde la celebración de referéndums abrogatorios se ha generalizado como contrapeso del legislador. En Suiza, procede su convocatoria si lo solicitan 50000 electores o simultáneamente ocho cantones en un plazo de cien días desde la aprobación de la ley federal discutida o de determinados tratados internacionales (art. 141 de la Constitución), y está previsto asimismo en los cantones, habiéndose celebrado en ambos ámbitos territoriales cientos de ellos. En Italia, el referéndum abrogatorio, total o parcial, de leyes o actos con fuerza de ley, puede celebrarse a iniciativa de 500000 electores o de cinco consejos regionales (art. 75 de la Constitución). También está regulado en varios estatutos regionales. En el ámbito regional su uso ha sido hasta la fecha marginal, pero no a escala nacional, donde, desde 1974, se han celebrado 67 referéndums abrogatorios sobre temas tan dispares y sensibles como el divorcio, la financiación pública de partidos, la despenalización del aborto, la investigación con embriones y fecundación asistida, el sistema electoral, la edad de jubilación, la energía nuclear, las privatizaciones del agua y los impedimentos procesales a favor de los miembros del Gobierno ${ }^{11}$.

En todas estas modalidades normativas de referéndum (propositivo, suspensivo y abrogatorio), la posibilidad reconocida a un número significativo de ciudadanos de trasladar la decisión normativa al cuerpo electoral influye decisivamente en el desarrollo y la capacidad de integración política del procedimiento legislativo ordinario (Gerber, 1996: 99-102). Estando legitimadas para solicitar la celebración de consultas populares, las minorías y las organizaciones de la sociedad civil pueden presionar a los partidos mayoritarios anunciando que, si sus demandas o preocupaciones nos son escuchadas por el legislador, están dispuestas a promover la convocatoria de un referéndum propositivo de normas, suspensivo o abrogatorio. Ello favorece la negociación e integración de los intereses en sede parlamentaria. Ante la incertidumbre del resultado en un referéndum, la mayoría parlamentaria tiende a ser receptiva a

11 Los referéndums abrogatorios italianos y sus respectivas participaciones, que no superaron el quorum mínimo exigido en los referéndums celebrados en el período de 1997 a 2009, en http://bit.ly/2v1SWsS. 
fin de evitar su convocatoria, o en el supuesto de producirse esta, esa mayoría suele mostrarse integradora, como ocurre en Suiza con las contrapropuestas parlamentarias que la Asamblea puede formular, que se someten a consulta simultáneamente con las proposiciones ciudadanas y suelen ser las preferidas de los votantes por su vocación y contenido conciliador ${ }^{12}$. Por las razones anteriores, el referéndum facultativo, en cualquiera de sus modalidades, representa un estímulo o acicate para la búsqueda continuada del compromiso entre las fuerzas políticas y entre estas y las organizaciones de la sociedad civil. Lejos de ser un instrumento potencialmente divisivo, el referéndum facultativo resulta políticamente centrípeto. Y puede funcionar, llegado el caso, como correctivo de la inactividad legislativa (en su modalidad propositiva) y del predominio y las disfuncionalidades parlamentarias (modalidades suspensiva y abrogativa): un correctivo que canalice e integre el descontento mediante la implicación popular en el proceso legislativo y la generación de una dinámica consensual.

\section{LAS PRINCIPALES GARANTÍAS NORMATIVAS DEL REFERÉNDUM: SU IMPLEMENTACIÓN EN EL DERECHO COMPARADO}

Los referéndums son un instrumento democrático que se inserta en el juego de los checks and balances en que descansa el Estado constitucional. Desde este punto de vista, son una institución de garantía, pero no siempre su utilización resulta oportuna. Lamentablemente, no todos los referéndums profundizan la democracia: depende de quién pregunte, sobre qué se pregunte y en qué condiciones se delibere en la campaña. Como De Vega (1985: 124125) señaló, la disfuncionalidad de los referéndums

[...] comienza cuando dejan de ser instrumentos correctores [...] de la democracia representativa, para convertirse en medios, a cuyo través, al sistema de legitimidad del Estado constitucional, se opone un sistema de legitimidad diferente. Dicho en otros términos, el problema del referéndum y de la iniciativa no es el de su reconocimiento y regulación por el ordenamiento constitucional, sino el del uso o el abuso que de ellos pueda hacerse por los propios poderes constituidos, cuando conculcando la lógica del sistema los utilizan en una perspectiva diferente y con unos fines distintos a los legalmente previstos.

12 "The referendum has given rise to the so-called 'politics of condordance', implying that all interest groups that are capable of imposing a veto through the rejective initiative are included in the legislative process» (Kriesi y Trechsel, 1996: 202). 
Aunque compatible con el parlamentarismo, el referéndum puede llegar a ser, usando el símil de Ruini (1953: 13), «un injerto plebiscitario en el tronco de la representación», por lo que su regulación ha de procurar minimizar los riesgos que su práctica inadecuada conlleva y que algunos de los referéndums celebrados recientemente - como el convocado en Grecia en plena negociación del tercer rescate de su economía, el referéndum sobre la salida de Reino Unido de la UE, el referéndum sobre las cuotas de refugiados demandantes de asilo en Hungría o el referéndum de reforma constitucional en Turquía- habrían puesto de manifiesto. A fin de evitar estos riesgos, entre los que la doctrina destaca la injerencia de las Gobiernos, el déficit en el proceso de deliberación y el posible atropello por la mayoría de los derechos de las minorías (Tierney, 2012: 23-27), en el derecho comparado se han generalizado e impuesto a los referéndums diversas garantías que pretenden minimizar las posibilidades de abuso por parte de los ostentadores del poder. Dichas garantías consisten en la ampliación de los sujetos dotados de iniciativa para instar su convocatoria, la exclusión de determinadas materias como objeto de consulta y las exigencias de quorum o de mayorías reforzadas para conferir validez al resultado.

\section{LA PLURALIDAD DE SUJETOS LEGITIMADOS PARA INSTAR SU CONVOCATORIA. EN ESPECIAL, LA INICIATIVA POPULAR DE REFERÉNDUM}

La cuestión de la iniciativa reviste una importancia capital, porque si solo el presidente o el Gobierno la poseen, la posibilidad de usar el referéndum como herramienta plebiscitaria es mucho mayor. "Cuando los Gobiernos controlan el referéndum — señaló Lijphart (1984: 204)—, tienden a usarlo solo cuando esperan ganar», lo que conduce al desprestigio de la democracia directa. A mayor número de sujetos proponentes, en cambio, esa tentación de utilización plebiscitaria se reduce y la funcionalidad del referéndum aumenta. Si el referéndum no lo controla ninguno de los agentes decisivos, como el Gobierno o la mayoría parlamentaria, entonces suma un poder corrector al sistema; en caso contrario, lo resta, pues refuerza a quien ya tiene el poder, suprimiendo la resistencia y los contrapesos de otros. De ahí la conveniencia de ampliar la iniciativa, otorgando legitimación a las entidades territoriales, a las minorías parlamentarias y, especialmente, a un número acreditado de ciudadanos ${ }^{13}$.

13 En este sentido, Penadés (2017) y Altman (2011: 2), quien reconoce que los plebiscitos impulsados «desde arriba» ofrecen a los jefes de Gobierno la oportunidad de esquivar 
El reconocimiento en los Estados descentralizados de la iniciativa de referéndum a las instituciones subcentrales de autogobierno propicia una mayor integración de los intereses territoriales en la voluntad general y modera las tendencias centralizadoras de la mayoría parlamentaria nacional. En Suiza, los referéndums facultativos sobre leyes, disposiciones federales y tratados internacionales pueden convocarse a solicitud de ocho cantones (art. 141.1 de la Constitución), y como señala la doctrina, esa facultad cantonal y su capacidad de movilización social en un referéndum refuerzan la integración de los intereses cantonales en las decisiones federales (Sáenz, 2016a: 94). En Italia, la legitimidad para instar la convocatoria se reconoce también a cinco consejos regionales en dos tipos de referéndum: en el potestativo de reforma constitucional (art. 138 de la Constitución) y en el legislativo abrogatorio (art. 75 de la Constitución). En España, el anteproyecto de Constitución elaborado por la ponencia en 1977 otorgaba asimismo legitimación para convocar referéndums a las asambleas de, al menos, tres CC. AA. Y en su primera redacción, más tarde modificada, dicha iniciativa autonómica figuraba en la proposición de reforma del art. 92 de la CE impulsada por la Junta General del Principado de Asturias, en el convencimiento de sus promotores de que la legitimación territorial incrementaría la implicación de las CC. AA. en las decisiones que afectan al todo ${ }^{14}$.

Por su parte, el reconocimiento de la iniciativa de referéndum a una minoría parlamentaria puede actuar de freno de la mayoría parlamentaria y estimular la negociación entre los grupos. Y si el referéndum es finalmente convocado a instancias de la minoría, puede servir para arbitrar eventuales conflictos entre mayoría y minoría en aquellos casos y materias en que el desacuerdo tenga también un amplio reflejo social. En Latinoamérica, Uruguay concede la posibilidad de instar la convocatoria de un referéndum de

la resistencia de otras instituciones democráticas y legitimar sus iniciativas con un barniz de popularidad. Por el contrario, los referendos impulsados «desde abajo», a través de las iniciativas populares especialmente, permiten a los ciudadanos confrontar a los gobernantes con nuevas demandas, cuestionando el monopolio de los políticos profesionales sobre la agenda de gobierno. Estos mecanismos de democracia directa impulsados por los ciudadanos, destaca el autor, «no buscan suplantar la democracia representativa, sino servir como válvulas de escape intermitentes en contra del comportamiento perverso o no-responsivo de las instituciones representativas».

14 Esta proposición de reforma constitucional fue admitida a trámite el 21 de octubre de 2014 y está pendiente de su toma en consideración (BOCG, Congreso de los Diputados, Serie B, núm. 194-1, 24 de octubre de 2014, pp. 1-3). En su primera redacción, posteriormente modificada, se reconocía la iniciativa de referéndum a 500000 electores, a ambas Cámaras y a las asambleas de tres CC. AA. 
reforma constitucional a dos quintos de los componentes de la Asamblea General (art. 331.B de la Constitución), y Ecuador reconoce idéntica iniciativa a un tercio de los miembros de la Asamblea Nacional (art. 441 de la Constitución). En Italia, la iniciativa para solicitar un referéndum facultativo de reforma constitucional se reconoce a una quinta parte de los miembros de cualquiera de las Cámaras (art. 138 de la Constitución). En España, la misma iniciativa se otorga a una décima parte de los diputados o senadores (art. 167.3 CE). Y en Dinamarca, un tercio de los miembros del Folketing puede instar la convocatoria de un referéndum de ratificación legislativa (art. 42.1 de la Constitución).

A diferencia de las iniciativas territorial y parlamentaria, cuyo reconocimiento y utilización son limitados, la iniciativa popular de referéndum está muy generalizada en el derecho comparado. Al amparo de esta iniciativa, un número absoluto de ciudadanos o un porcentaje de ellos puede determinar la celebración de un referéndum sobre una cuestión política de interés general o sobre un producto normativo, remitiendo a los ciudadanos la decisión definitiva sobre su oportunidad política, su aprobación o su abrogación.

La iniciativa popular de referéndum está reconocida en veinticuatro estados de EE. UU. La mayoría de ellos ha optado por la iniciativa directa, que supone que las propuestas válidamente suscritas por un porcentaje de ciudadanos inscritos en el censo electoral o por un porcentaje calculado sobre el número de votos emitidos en alguna de las últimas convocatorias electorales (a gobernador del Estado, presidenciales o generales) deben someterse necesariamente a votación popular. En otros estados, en cambio, las propuestas normativas de los ciudadanos son remitidas al Parlamento para su deliberación y votación. Y si en un plazo determinado - que oscila entre los cuarenta días en Michigan y Nevada hasta el fin de la legislatura en Maine- no son asumidas por los representantes políticos, deben someterse a referéndum. En Utah y Washington los promotores de las iniciativas pueden escoger entre ambos modelos. En Massachusetts, el Parlamento puede presentar un proyecto alternativo, que se somete a votación junto con la propuesta ciudadana ${ }^{15}$. Y en California, donde la iniciativa es directa y más referéndums se celebran, desde septiembre de 2014 se permite que los promotores puedan retirar su propuesta en caso de obtener una respuesta satisfactoria de las instituciones representativas, lo que estimula la receptividad de la clase política, así como la negociación y el pacto previos a la convocatoria de referéndum. En Nueva Zelanda, la Citizens Initiated Referenda Act 1993 ha reconocido la iniciativa

15 Sobre las singularidades de las iniciativas en los diversos estados, Tarr (1998: 118-126) y Donovan (2014: 122-153). 
de referéndum sobre cuestiones nacionales a un $10 \%$ de los inscritos en el censo electoral. En Latinoamérica, Uruguay, Colombia, Costa Rica y Ecuador han incorporado en sus constituciones la iniciativa popular de referéndum propositivo de reforma constitucional y de referéndum abrogatorio de leyes a un porcentaje del cuerpo electoral. Venezuela, por su parte, ha previsto la iniciativa popular para el referéndum abrogatorio y para los referéndums sobre cuestiones de especial trascendencia. En el caso de la iniciativa de reforma constitucional, el porcentaje de solicitantes oscila entre el $5 \%$ de electores exigido en Colombia (art. 374 de la Constitución) y Costa Rica (art. 105 de la Constitución) y el $10 \%$ requerido en Uruguay (art. 331.A de la Constitución). En el caso de la iniciativa abrogatoria, el porcentaje varía entre el $5 \%$ de los inscritos en el Registro Electoral en Ecuador (art. 104 de la Constitución) y Costa Rica (art. 105 de la Constitución) y el $25 \%$ requerido en Uruguay (art. 79 de la Constitución).

La iniciativa popular de referéndum también está muy extendida en Europa. En Suiza, la mayoría de los referéndums son resultado de iniciativas populares impulsadas por, al menos, 100000 ciudadanos en caso de reformas constitucionales (arts. 138 y 139 de la Constitución) o por 50000 ciudadanos para los referéndums facultativos sobre leyes y disposiciones federales en vigor o sobre tratados internacionales (art. 141 de la Constitución). En Italia, 500000 electores pueden solicitar la convocatoria de un referéndum facultativo de reforma constitucional (art. 138 de la Constitución) y el mismo número de firmantes se exige para solicitar la convocatoria de los referéndums abrogatorios de leyes o actos con fuerza de ley (art. 75 de la Constitución). En los Länder alemanes la iniciativa popular de referéndum se reconoce a un porcentaje del cuerpo electoral de cada $L a n d$, que oscila entre el $4 \%$ exigido en Brandemburgo y el $20 \%$ en Berlín, Bremen y Saarland. En Hungría se convoca automáticamente referéndum si la solicitud va firmada por más de 200000 ciudadanos; y con el concurso de la mayoría de la Asamblea si ha sido solicitado por menos de 200000 pero más de 100000 electores (art. 8.1, «El Estado», de la Ley Fundamental). Países Bajos otorga la iniciativa de referéndum sobre cualquier asunto de interés nacional a 300000 ciudadanos (Wet raadgevend referendum op 1 julio 2015) y Polonia la otorga a 500000 ciudadanos. Rusia confiere la iniciativa para referéndums legislativos y sobre asuntos de interés nacional a dos millones de electores que han de estar distribuidos entre la mitad de las unidades territoriales de la Federación. Y Lituania, en fin, la reconoce para referéndums consultivos y legislativos a 300000 electores (Ley IX-929/2002, de 4 de junio ${ }^{16}$ ).

16 Francia y Portugal también admiten la iniciativa popular de referéndum, pero en ambos debe ser perfeccionada o completada en sede parlamentaria. En Portugal, la 
En el plano teórico, alguna doctrina considera que el ejercicio de la iniciativa popular de referéndum puede cuestionar la función de mediación de los partidos políticos y provocar un choque de legitimidades entre el cuerpo electoral y sus representantes (Morel, 1993: 225-244). Las experiencias suiza y uruguaya demuestran, sin embargo, que el ejercicio de la iniciativa popular de referéndum refuerza las estructuras de los partidos, que operan como activos agentes en la campaña, y les permite erigirse en verdaderos vehículos de mediación y de formación de la voluntad general. Y lo mismo ocurre en Italia con ocasión de las iniciativas populares de referéndums debido a la gran capacidad de movilización y organización de los partidos (Sáenz, 2016b: 133-134; Rolla, 2017: 222-224). En relación con la segunda cuestión, coincidimos con De Vega (1985: 118) en rechazar la supuesta pugna de legitimidades entre el cuerpo electoral y el Parlamento:

«Frente a $[\ldots]$ quienes ven en el referéndum — afirma el autor — un elemento distorsionante de la democracia representativa, por el hecho de poner a veces de manifiesto la discordancia entre el país legal (las Asambleas) y el país real, hay que recordar que el fundamento y la grandeza de la institución radica en la pretensión de evitar que la voluntad del pueblo, expresada a través de las Asambleas, pueda ser trastocada por estas y convertida en su única soberana voluntad».

La iniciativa de referéndum complementa la lógica de la representación. Es más, la legitima al hacerla verosímil, porque, como subrayó Carré de Malberg (2014: 298), no cabe defender la idea de que la representación hace presente la voluntad popular y no reconocer al tiempo «el derecho de los ciudadanos a manifestar un sentimiento distinto a aquel que, sobre una cuestión determinada, ha sido manifestado en su nombre por los representantes». No reconocerlo, sería «sustituir con la soberanía parlamentaria la soberanía del cuerpo electoral de los ciudadanos» y sustraer las decisiones del órgano legislativo a la voluntad de estos últimos, que son el fundamento de su legitimidad.

La práctica comparada evidencia, además, que el ejercicio de la iniciativa popular no socava la representatividad parlamentaria. Al contrario, estimula la

propuesta popular de referéndum debe ir suscrita por un número no inferior a 75000 ciudadanos y ha de contar con el apoyo de la mayoría simple de la Asamblea (art. 115.2 de la Constitución y art. 16 de la Ley Orgánica 15-A/1998, de 3 de abril). En Francia, la iniciativa popular se otorga a una décima parte del cuerpo electoral y ha de ser compartida por una quinta parte de los miembros de la Asamblea Nacional (art. 11 de la Constitución). Al exigirse la concurrencia de dos voluntades, la iniciativa compartida no ha sido usada y en ambos países se ha abierto el debate sobre su conversión en una auténtica iniciativa popular. 
receptividad hacia las demandas sociales y opera como un factor dinamizador de la relación representativa. Trabajos empíricos sobre el reconocimiento de esta iniciativa evidencian que la acción legislativa y de gobierno tiende a acercarse más a las preferencias de los votantes en los lugares donde existe que en donde no se reconoce (Gerber, 1996: 99). En los primeros, la distancia entre los ciudadanos y las instituciones se reduce y se incorporan asuntos a la agenda parlamentaria que no figuraban con anterioridad o no eran recogidos por los grupos políticos. Un ejemplo reciente ha tenido lugar en California. El aumento del salario mínimo a 15 dólares/hora no lo había solicitado ninguna fuerza política, pero el sindicato de salud planteó una iniciativa popular al respecto. A mediados de marzo de 2016 el sindicato anunció que ya tenía firmas suficientes para que se votara su propuesta. En una semana, el gobernador y el Legislativo se sentaron con los promotores y pactaron una ley un poco más matizada (un ańo de plazo para llegar a 15 dólares y la posibilidad de frenar la subida si la economía se estanca) que ha podido ser presentada como un éxito de todos y ha evitado que la iniciativa fuera votada. Y similar dinámica negociadora se genera en otros Estados en los que se ejercita la iniciativa popular, como en Uruguay, los Länder alemanes y Suiza, donde, como señala Sáenz (2016a: 92) refiriéndose al caso suizo, «cualquier propuesta es debatida antes de su consideración parlamentaria por un amplio sector institucional y social (partidos, cantones y grupos de interés)» a fin de «asegurar que todos los intereses afectados por la nueva regulación - y especialmente los actores capaces de presentar una amenaza creíble de referéndum - tengan la oportunidad de dar su opinión y ser oídos [...]». Y cuando las iniciativas populares ya se han puesto en marcha se abre un proceso de «negociación ex post que puede incorporar parcialmente las demandas o bien directamente en un contraproyecto parlamentario de reforma constitucional o bien indirectamente a través de una modificación legislativa», creando vías de diálogo institucionalizado entre la sociedad civil y el Parlamento que han posibilitado la configuración de una democracia consensual.

\section{LAS CUESTIONES EXCLUIDAS DE LA INICIATIVA DE REFERÉNDUM Y EL CONTROL DE ADMISIBILIDAD}

Todo poder democrático debe ser un poder limitado, incluido el poder de decisión en referéndum. Por ello, al igual que el Parlamento tiene en ciertos ordenamientos materias vedadas a su intervención, cuya iniciativa corresponde a otros órganos, y ha de respetar el contenido esencial de los derechos fundamentales y los compromisos internacionales en su tarea de creación del derecho, también deben existir límites materiales para el referéndum a fin evitar su utilización como instrumento para socavar los fundamentos de 
la democracia y los derechos de las minorías. A tal efecto, varios países han previsto diversas exclusiones materiales del ámbito de la decisión popular en referéndum.

La Constitución de Dinamarca prohíbe que sean sometidos a referéndum los proyectos de ley que traten del presupuesto ordinario, del presupuesto extraordinario o del provisional, los que autoricen empréstitos del Estado o establezcan impuestos, los que fijen retribuciones o pensiones de jubilación y los relativos a la Corona, a la nacionalidad y a la observancia de obligaciones contraídas por tratado (art. 42.6). En Italia, la Constitución no permite el referéndum abrogatorio sobre leyes tributarias y presupuestarias, de amnistía e indulto o de autorización para ratificar tratados internacionales (art. 75.2), y la Corte Constituzionale, en el ejercicio de su facultad de control, ha ampliado interpretativamente dichos límites, excluyendo también de referéndum las leyes de reforma constitucional, otras leyes constitucionales y los actos legislativos reforzados que no puedan ser derogados por leyes ordinarias, las «disposiciones legislativas ordinarias con contenidos constitucionalmente vinculados» — que han sido definidas como aquellas «cuyo contenido no puede alterarse o suprimirse sin producir el mismo efecto en alguna disposición de la Constitución» o cuya derogación «priva totalmente de eficacia a un principio u órgano constitucional» (Sentencia núm. 27/1987) — y las disposiciones que producen efectos vinculados a las materias que el artículo 75.2 de la Constitución enumera ${ }^{17}$. En Portugal, el artículo 115.4 de la Constitución excluye de referéndum las cuestiones y los actos de contenido presupuestario, tributario y financiero y, por remisión a los arts. 161 y 164 de la Constitución, tampoco puede consultarse sobre los estatutos de las regiones autónomas, las amnistías e indultos, los proyectos de planificación económica, los empréstitos y operaciones de crédito del Estado, la aprobación de tratados, la nacionalidad, el régimen electoral y el régimen jurídico del referéndum, de las asociaciones y partidos, de la jurisdicción constitucional, de la defensa nacional y de las FAS. En Polonia, la iniciativa popular no puede cuestionar los presupuestos, los tributos, la defensa nacional y la amnistía, según la Ley de Consultas Ciudadanas y Referéndum de 23 de marzo de 2003, aunque estos temas sí pueden ser objeto de referéndum si la iniciativa parte de la Dieta o del presidente. Y en Hungría, la iniciativa popular de referéndum no puede afectar a las disposiciones constitucionales, los presupuestos, los tributos, las obligaciones impuestas por tratados internacionales y las declaraciones de excepción (art. 8.2, «El Estado», de la Ley Fundamental de 2011).

17 Sobre la ampliación por vía jurisprudencial de los límites materiales, Requejo, 2013: 218-22. 
En Latinoamérica, las reformas constitucionales que han impulsado la democracia directa han optado por regular, asimismo, límites materiales a los referéndums. En Ecuador, están vetadas las iniciativas de referéndums de reforma constitucional parcial que establezcan restricciones a los derechos y garantías o modifiquen el procedimiento de reforma constitucional (arts. 441 y 442 de la Constitución). En Uruguay, no cabe el referéndum abrogatorio de leyes sobre cuestiones tributarias (art. 79 de la Constitución). En Colombia no pueden someterse a referéndum las leyes de carácter tributario y presupuestario ni los tratados internacionales en vigor (art. 170 de la Constitución). Y en Perú, a las exclusiones previstas en Colombia, se añade la prohibición de las iniciativas que pretendan la supresión o disminución de los derechos fundamentales (art. 32 de la Constitución). En EE. UU., algún estado también excluye de la iniciativa popular de referéndum una amplia lista de materias, como Massachusetts (enmienda XLVIII, II, secc. 2 de su Constitución), donde no cabe la iniciativa en materia de derechos constitucionales, ingresos del tesoro, nombramiento y remoción de jueces o revocación de decisiones judiciales. Otros estados, como Mississippi, vetan las iniciativas que pretendan cambiar la declaración estatal de derechos ${ }^{18}$. En la mayoría de estados federados, sin embargo, puede votarse en referéndum a iniciativa popular la regulación o abrogación de cualquier materia de competencia estatal, sin límite alguno. Como consecuencia de ello, en California fue aprobada en 1978 la célebre Proposición 13, que congeló los impuestos sobre la vivienda y que condujo, junto con la aprobación de otras iniciativas de reducción de impuestos e incremento simultáneo del gasto, a la bancarrota del estado. También en California se aprobó en 2008 la Proposición 8, que prohibía el matrimonio entre personas del mismo sexo recientemente legalizado. La prohibición adoptada en referéndum era abiertamente inconstitucional y tuvo que intervenir la jurisdicción federal para derogarla. Y lo mismo ocurrió años antes con la Proposición 187, que vetaba a los inmigrantes indocumentados el acceso a la sanidad y a la educación y fue anulada posteriormente por los tribunales.

En Suiza, el único límite a las iniciativas populares es que no contravengan «las reglas imperativas del derecho internacional» (art. 139.3 de la Constitución). Si lo hacen, la Asamblea Federal puede declararlas inválidas y rechazar la celebración de referéndum. Pero si una iniciativa vulnera un tratado o normas internacionales que no sean ius cogens, la Asamblea está obligada a tramitarla. Eso explica que en 2009 fuera convocado el referéndum que vetó la construcción de minaretes en el país, decisión que cuestionaba la libertad de culto amparada por los arts. 9 y 14 del Convenio Europeo de Derechos

18 Sobre estos límites, Donovan, 2014: 130-131. 
Humanos, y que en 2010 fuera autorizada en referéndum la deportación automática de extranjeros condenados por delitos graves, medida que vulneraba garantías jurídicas previstas en acuerdos internacionales suscritos por la Confederación.

Estos polémicos referéndums sobre tributos y restricción de derechos han impulsado el debate sobre la necesidad de establecer límites materiales en las regulaciones nacionales que no las prevean y, allí donde ya están previstos, sobre la oportunidad de incrementarlos. Un amplio sector doctrinal coincide en que las cuestiones presupuestarias y tributarias, la amnistía e indulto, la regulación de la nacionalidad y la autorización para ratificar tratados internacionales son susceptibles de manipulación demagógica por minorías activas y deberían estar vedadas a la iniciativa popular de referéndum, sin perjuicio de que puedan ser sometidas en su caso a referéndum a iniciativa de los Gobiernos o los Parlamentos. El debate está abierto, sin embargo, en relación con la inclusión o no entre esos límites de las iniciativas relativas a derechos en general o que afecten a los derechos de las minorías no concentradas geográficamente, que podrían quedar vulnerados si la decisión sobre el ejercicio de sus derechos o sobre su contenido esencial puede ser adoptada en referéndum sin cortapisas constitucionales. La idea que subyace en la propuesta de este límite es que unos ciudadanos no pueden votar desproveer a otros de sus derechos de ciudadanía en una parte o en todo el territorio político compartido. Autores como Benoît proponen por ello prohibir cualquier iniciativa de referéndum que afecte a los derechos reconocidos en el Convenio Europeo de Derechos Humanos, o las que puedan afectar a los derechos fundamentales regulados en la constitución del Estado, como se prevé en Massachusetts y Mississippi o como para Suiza ha postulado Daniel Vischer, miembro de la Comisión de Política Institucional del Consejo Nacional ${ }^{19}$. Para los contrarios a la inclusión de esta prohibición, en cambio, excluir de referéndum la adopción de cualquier decisión en materia de derechos supondría, por la vis expansiva de los mismos, la imposibilidad de impulsar iniciativas populares sobre un amplio e indeterminado número de cuestiones conexas, que en la práctica abocaría al referéndum de iniciativa popular a la marginalidad. A fin de evitarlo, la limitación, al igual que afecta al legislador en varios ordenamientos comparados (v. gr. art. 53.1 CE), podría reducirse al respeto del contenido esencial de los derechos, que debería ser apreciado en un juicio de admisibilidad de la iniciativa por parte de la jurisdicción constitucional o de otro órgano de garantía. El debate, en cualquier caso, está abierto.

19 Las tesis de Benoît y Vischer pueden verse en Gonin (2014) y Josi (2014). 
Lo que la doctrina no discute es la necesidad de implementar como corolario lógico un riguroso control de admisibilidad previo a la convocatoria de referéndum que garantice que las materias excluidas quedan realmente fuera del ámbito de decisión popular. En Hungría, es la Comisión Electoral Nacional la encargada de garantizar que las iniciativas de referéndum no incidan en las materias excluidas (art. 28/C5 de la Constitución). En Massachusetts, esa función de control se atribuye al fiscal general del Estado (Attorney General). Y en Suiza, el examen de validité de las iniciativas se asigna a la Asamblea Federal. En una mayoría de Estados, sin embargo, el control sobre las condiciones de admisibilidad de la iniciativa popular se atribuye a la justicia constitucional. Así se prevé en Italia, donde la Ley Constitucional núm. 1 de 11 de marzo de 1953 encarga a la Corte Constitucional el control sobre el respeto de los límites materiales impuestos en el artículo 75 de la Constitución, cuyo alcance ha ampliado interpretativamente (Olivetti, 2007: 157-158). En Portugal, la fiscalización preventiva de la constitucionalidad y legalidad de las iniciativas de referéndum, especialmente sobre la pregunta y los ámbitos materiales excluidos, corresponde al Tribunal Constitucional (art. 115.8 de la Constitución). En Uruguay, es la Suprema Corte de Justicia la encargada de velar por la constitucionalidad de las materias consultadas (art. 239.1 de la Constitución). En Colombia corresponde a la Corte Constitucional decidir sobre la constitucionalidad de la convocatoria del referéndum de reforma constitucional (art. 241.1 de la Constitución), un control que la importante Sentencia C-551/2003 de la Corte ha extendido a las materias excluidas de referéndum. Y en Ecuador, la Corte Constitucional emite un dictamen previo y vinculante de constitucionalidad de la convocatoria de referéndum tanto a nivel nacional como autonómico (art. 443 de la Constitución). En todos estos casos, el control es preceptivo y no cabe convocatoria sin un pronunciamiento favorable sobre el objeto de la consulta.

\section{PARTICIPACIÓN POPULAR MÍNIMA Y EXIGENCIA DE MAYORÍAS REFORZADAS}

En el derecho comparado, numerosos Estados supeditan la validez o el carácter vinculante de los referéndums a la superación de un determinado quorum o porcentaje mínimo de participación popular. Estas exigencias pretenden evitar la adopción de decisiones colectivas, en ocasiones irreversibles y de especial trascendencia para la comunidad, en referéndums en los que la participación sea escasa e insuficientemente representativa en relación con el censo o con la participación habida en las elecciones y la representatividad institucional resultante.

Así, en Italia, el referéndum legislativo abrogatorio carece de validez si el número de votantes es inferior al $50 \%$ de los inscritos en el censo 
electoral (art. 75 de la Constitución). Dicho quorum, que no se exige en cambio para el referéndum de reforma constitucional (art. 138 de la Constitución), se alcanzó con holgura de 1977 a 1996, pero a partir de ese momento, y durante más de una década, cundió la táctica de los opositores de los diferentes referéndums de invitar a los electores a no acudir a las urnas, superándose tan solo el porcentaje de validez requerido en los referéndums abrogatorios de 2011. En Hungría, los referéndums solo eran considerados válidos si el número de votos emitidos en sentido positivo o negativo superaba el $25 \%$ del cuerpo electoral (art. 28-C, 6 de la Constitución de 1949). Tras la nueva Ley Fundamental de 2011, solo es válido si han participado más de la mitad de los inscritos en el censo (art. 8.4, «El Estado», de la Ley Fundamental). En Portugal, el quorum de participación no condiciona la validez del referéndum, pero sí su carácter vinculante para los órganos constitucionales, que solo están obligados a acatar el resultado cuando el número de sufragios supera la mitad de los electores inscritos en el censo (art. 115.11 de la Constitución). En Dinamarca, los proyectos o proposiciones de ley sometidos a referéndum legislativo se consideran rechazados si existe una mayoría de votos en contra y esta representa, al menos, el 30\% del censo electoral (art. 42.5 de la Constitución). En Países Bajos, la ley exige para la validez del referéndum que la participación supere el $30 \%$ del censo electoral. Los Länder alemanes, con la excepción de Baviera, Hesse y Sajonia, exigen para conferir validez a los referéndums legislativos entre un $15 \%$ (caso de Renania del Norte-Westfalia) y un $50 \%$ de participación (Saarland) calculado sobre el censo; y en los referéndums de reforma constitucional (regulados en todos los Länder menos en Hesse y Saarland), el quorum exigido oscila entre el $25 \%$ (Baviera), el $40 \%$ (Turingia) y el $50 \%$ de participación (el resto de Länder).

A diferencia de los casos anteriores, en algunos estados de EE. UU. el porcentaje de participación requerido para otorgar validez a los referéndums se fija en relación con el número de sufragios alcanzados en alguna de las últimas convocatorias electorales o en las elecciones (a gobernador, presidenciales o generales) con las que coincide el día de la votación de la iniciativa. En Nebraska y Mississippi se exige una participación del 35\% y el $40 \%$, respectivamente, del total de votos emitidos en las últimas elecciones. En Massachusetts, las propuestas legislativas y constitucionales solo se consideran aprobadas cuando la cantidad de votos favorables es superior al $30 \%$ de los sufragios emitidos en las elecciones generales que se celebran el mismo día de votación del referéndum. Y en Wyoming se exige que concurra una mayoría de votos calculada sobre los votos emitidos en las elecciones celebradas simultáneamente, esto es, el $50 \%$ de quorum y también de votos afirmativos sobre la participación electoral. 
Las referidas exigencias de quorum persiguen que la voluntad popular expresada sea significativa para poder imponerse; que dicha voluntad no resulte excesivamente minoritaria en el cómputo global, porque en ese caso el referéndum puede adolecer de un claro déficit de legitimidad frente a la decisión representativa que reemplaza. Recientes experiencias en este sentido abonan, incluso, que algunos porcentajes de participación sean aumentados, como el previsto en los Países Bajos, donde el debate se ha suscitado a raíz del referéndum celebrado el 6 de abril de 2016, en el que se rechazó el acuerdo de cooperación suscrito entre la UE y Ucrania. La participación en este referéndum alcanzó el 32,2\% del censo, superando el 30\% requerido, pero el $61 \%$ de los sufragios en contra del acuerdo equivalían solo al $20 \%$ de los votantes sobre censo, que son el mismo porcentaje de ciudadanos que representan los partidos minoritarios que rechazaron el acuerdo en sede parlamentaria frente a la mayoría del Parlamento holandés. En opinión de las principales fuerzas políticas, el referéndum, con una abstención casi del $70 \%$ del censo, supuso un retroceso democrático y la imposición de la decisión directa de una minoría sobre la decisión parlamentaria representativa de una mayoría de electores.

Pese a las razones que para parte de la doctrina justifican la exigencia de una participación mínima, e incluso su incremento, el Code of Good Practice on Referendums (punto 7), elaborado por el Consejo de Europa ${ }^{20}$, sostiene que fijar un quorum equivale a computar a los abstencionistas como si fueran votantes del «no», lo que sería improcedente desde el punto de vista de la voluntad popular expresada. Según el memorándum incluido en el Code, la fijación de quorums puede impulsar estratégicamente a los opositores de la propuesta a abstenerse en vez de votar en contra (punto III.7.a). El eventual voto estratégico no arrumba, sin embargo, la necesidad de evitar la adopción de decisiones colectivas a partir de una participación escasa o insuficientemente representativa; una necesidad de legitimidad que, a nuestro juicio, ampara la exigencia de quorum.

Abundando en la idea de que la voluntad popular expresada en referéndum debe ser significativa para imponerse, algunos Estados han incorporado la exigencia de mayorías reforzadas del cuerpo electoral o de mayorías dobles, del cuerpo electoral general y de un número de territorios, para considerar válidamente adoptadas decisiones políticas de especial trascendencia, como las relativas a derechos fundamentales, reformas constitucionales o divisiones y secesiones territoriales.

20 El Code of Good Practice on Referendums, adoptado por el Consejo para Elecciones Democráticas en su 19. ${ }^{a}$ reunión (Venecia, 16 de diciembre de 2006) y la Comisión de Venecia en su 70. ${ }^{a}$ sesión plenaria (16-17 de marzo de 2007). Disponible en: http://bit.ly/2vrokk0. 
En Reino Unido, la denominada «enmienda Cunningham» incorporada a los proyectos de ley ad hoc para Escocia y Gales de 1978 exigió que la devolution debía ser aprobada en referéndum por más de un $40 \%$ de los electores (Harvey, 2017: 67), porcentaje que no se superó en los referéndums celebrados al año siguiente. En Dinamarca, el art. 88 de la Constitución requiere una mayoría favorable superior al $40 \%$ del censo electoral para considerar aprobada una reforma constitucional. En Uruguay, los votos afirmativos deben superar la mayoría absoluta de los sufragios emitidos y representar, por lo menos, el 35\% del total de inscritos en el Registro Cívico Nacional (art. 331 de la Constitución). Y los Länder alemanes de Berlín, Brandemburgo, Hamburgo, Renania del Norte-Westfalia, Sajonia-Anhalt y Schleswig-Holstein exigen, por su parte, para la validez de la reforma constitucional, el voto afirmativo de una mayoría de dos tercios de los electores. En el mismo sentido se expresa la Clarity Act/Loi de Clarification, de 29 de junio de 2000, recogiendo la doctrina del Reference re Secession of Quebec de la Corte Suprema de Canadá21, en caso de celebrarse un nuevo referéndum de secesión en la provincia de Quebec, para cuya aprobación se precisa «una clara expresión de una clara mayoría de la población de esa provincia» [s.2(1) Clarity Act].

Para la validez de los referéndums de revisión constitucional, de adhesión a organizaciones o comunidades supranacionales y sobre leyes federales urgentes con validez superior a un año, Suiza exige, por su parte, la concurrencia de una doble mayoría, esto es, que una mayoría simple de votantes inscritos en el censo federal se pronuncie a favor y que también lo hagan los votantes de una mayoría de cantones, contando a estos efectos veinte de los cantones un punto y los seis cantones restantes, medio punto cada uno (art. 142 de la Constitución). En Australia también se requiere una mayoría doble de votos a favor en el cómputo global de la federación y en al menos cuatro de los seis estados federados. En los referéndums de reforma electoral celebrados en 2005 en la Columbia Británica y en 2007 en Ontario, la ley de referéndum exigió una mayoría favorable superior al $60 \%$ de los votos emitidos y en un $60 \%$ de los distritos electorales. Y en la misma línea, en Reino Unido, el Scottish National Party pretendió, mediante una enmienda presentada durante la tramitación parlamentaria de la European Union Referendum Act 2015, exigir una doble mayoría de votos para conferir validez a una eventual decisión de abandono de la UE en el referéndum sobre el brexit: la mayoría de votos en el cómputo global de Reino Unido y también en cada una de las naciones que lo integran, en atención a la trascendencia de la cuestión a decidir y sus consecuencias irreversibles. Lamentablemente, la enmienda fue rechazada (Castellà, 2016: 318).

21 Disponible en: http://bit.ly/2Apu3fY. 
El requerimiento de mayorías cualificadas o de mayorías dobles supone la protección de materias políticamente fundamentales y de especial transcendencia frente a coyunturales mayorías simples, y resulta, por ello, totalmente congruente con el principio democrático y con el de rigidez constitucional. Tan congruente como es la exigencia a las Asambleas constituyentes de mayorías reforzadas de dos tercios o tres cuartos para considerar aprobada una reforma constitucional, y lo es, asimismo, la exigencia al legislador de mayorías cualificadas, como la mayoría absoluta o superiores, para poder legislar sobre determinadas materias. Estamos, por ello, ante una auténtica garantía normativa del referéndum que refuerza la funcionalidad democrática de la institución y que debería implementarse como requisito imprescindible para la adopción de decisiones caracterizadas por su irreversibilidad, su alcance para las generaciones futuras o sus repercusiones internacionales, tales como las decisiones sobre derechos fundamentales, reforma constitucional, secesión territorial o unión de Estados y abandono de organizaciones internacionales. Convencidos de ello tras el triunfo del leave por escaso margen en el referéndum de 23 de junio de 2016, 4,1 millones de británicos suscribieron una petición dirigida al Parlamento para que convocara un nuevo referéndum sobre la permanencia o salida de Reino Unido de la UE en el que se exigiera una mayoría reforzada del $60 \%$ de los votos emitidos para considerar aprobado el brexit. La petición fue rechazada porque llegaba tarde. La decisión de abandonar la UE ya había sido tomada al amparo de la EU Referendum Act y, según el Parlamento británico, debía ser respetada ${ }^{22}$.

\section{CONSIDERACIONES FINALES}

En el derecho comparado, el uso del referéndum se ha generalizado en los últimos ańos y se ha extendido en todos los niveles de gobierno. Ello ha evidenciado que el referéndum puede complementar la democracia representativa, estimulando su representatividad y actuando de contrapeso. Su indiscutible éxito, sin embargo, no ha impedido su cuestionamiento. En los dos últimos ańos, especialmente, se han celebrado varios referéndums cuya convocatoria y resultados han sido polémicos, como el referéndum sobre el rescate de la economía griega, el brexit británico y los referéndums sobre las cuotas de refugiados y sobre el acuerdo de cooperación entre la UE y Ucrania celebrados, respectivamente, en Hungría y Países Bajos, entre otros.

22 La petición EU Referendum Rules triggering a 2nd EU Referendum y el debate suscitado en el Parlamento de Reino Unido pueden verse en http://bit.ly/2LPdONS. 
Para alguna doctrina, esta proliferación de referéndums y las nuevas convocatorias solicitadas amenazan el proyecto europeo y la estabilidad de nuestros delicados sistemas democráticos. «En sociedades grandes y complejas con intereses muy heterogéneos, la única democracia posible es la representativa; el vínculo directo entre gobernantes y "pueblo" no es democrático", ha afirmado contundente Maravall (2017). Los referéndums, afirma Urquizu (2014), son magníficos instrumentos de manipulación política y de evasión de responsabilidades, empobrecen el proceso deliberativo y debilitan a los representantes electos. Y Laporta (2016) ha sostenido que consultar al pueblo es un método de toma de decisiones temerario, confuso y simple que puede llevar a soluciones erróneas e irreversibles. «[...] esta supuesta variante de la democracia acaba por generar un veredicto político deformado por la ignorancia, la información sesgada y la alteración emocional». Para Laporta: «Nada hay de fundamental o cimentado en el resultado de un referéndum. Es dudoso que estemos en presencia siquiera de una decisión; se trata de la agregación artificial de preferencias individuales mediante un algoritmo tosco. Pero aunque fabulemos la decisión de un sujeto colectivo, eso no la torna en una decisión fundada ni anclada en principios incontestables de legitimidad».

Evidentemente, el referéndum no es la panacea y su empleo plantea algunos problemas que es preciso conocer para poder conjurar, pero poco ayuda a ese objeto recuperar argumentos como los expuestos, escasamente compatibles con el principio democrático. Como señala Ovejero (2016), muchas de las críticas a los referéndums también podrían servir para descalificar a la democracia parlamentaria: "Toda votación, incluidas las parlamentarias, al final, es dicotómica: sí/no; los parlamentarios padecen sesgos cognitivos o informativos; la manipulación estratégica es una posibilidad y hasta un hábito parlamentario; y la incompetencia agregada de los votantes no es inferior a la de los representantes». En ocasiones, como en los referéndums sobre el brexit o sobre el acuerdo entre la UE y Ucrania, los ciudadanos deciden en contra de las opciones consideradas obviamente correctas por las élites. Pero no por ello deben ser tildados de equivocación o fracaso de la democracia, ni resulta admisible atribuir la decisión mayoritaria a la ignorancia o la irracionalidad de los votantes.

Estas críticas ignoran, además, la experiencia comparada y la indiscutible hoja de servicios que el referéndum viene prestando en un buen número de países, donde contraponer la participación directa a la representación constituye un falso dilema. En Uruguay, los referéndums han servido para consolidar la democracia y defender el Estado social (Altman, 2011: 140-162). En Italia, el referéndum abrogatorio constituye uno de los rasgos distintivos de su sistema político, y su efecto, cuando se logra superar el quorum requerido, ha sido integrador, porque, frente a las iniciativas abrogatorias, los electores han 
confirmado normalmente la opción legislativa del Parlamento, con excepción de los referéndums promovidos durante la crisis del sistema de partidos (1993) o el caso de la consulta contra la energía nuclear (1987), celebrada tras el accidente de Chernóbil (Rolla, 2017: 223). En Suiza, aproximadamente el 93\% de las leyes susceptibles de referéndum son aprobadas por el Parlamento, y ha sido precisamente la posibilidad atribuida a los ciudadanos de instar a la celebración de referéndums lo que ha reforzado la negociación en sede parlamentaria ante cualquier propuesta de nueva regulación; en la mayoría de los casos antes de que las iniciativas fueran presentadas, pero también después de haberse presentado, integrándose posiciones a través de los contraproyectos parlamentarios que se someten a consulta con las iniciativas o mediante reformas legislativas parciales (Kriesi y Trechsel, 1996: 202). E idéntica función integradora ha desempeñado la democracia directa en los estados norteamericanos en que existe la iniciativa popular de referéndum, en los que solo una minoría de leyes resultan aprobadas, modificadas o derogadas por decisión refrendataria y en los que la mera posibilidad de convocar a consulta al cuerpo electoral estimula el compromiso a fin de evitar su activación y ante la incertidumbre del resultado.

El referéndum no es, por tanto, ese pretendido engendro confuso y simple, alimentado por «la ignorancia, la información sesgada y la alteración emocional» (Laporta, 2016). Por el contrario, se trata de un instrumento complementario valioso para las democracias representativas, a las que puede ayudar a través de su dimensión inclusiva y al que debe ayudarse con garantías jurídicas para reforzarlo en su dimensión deliberativa. El referéndum puede ser un acicate de la representatividad y un eficaz contrapeso del predominio parlamentario mediante el que poder discutir bien, ocasionalmente, algunas cuestiones y llegar a decidirlas directamente de forma colectiva. Los referéndums pueden servir para mejorar el autogobierno del pueblo, y deben ser valorados en la medida en que lo hagan, lo que depende de la eficacia de sus garantías. El dilema hoy, por tanto, no debería ser democracia representativa versus democracia directa, sino bajo qué fórmulas y con qué garantías la democracia parlamentaria puede incorporar a sus esquemas institucionales la práctica del referéndum.

\section{Bibliografía}

Altman, D. (2011). Direct democracy worldwide. New York: Cambridge University Press.

Barret, G. (2014). The use of referendums in Ireland: looking back in a time of fiscal crisis. En M. Contreras y E. Sáenz (coords.). La participación politica directa. Referéndum y consultas populares (pp. 93-128). Zaragoza: Comuniter.

Bobbio, N. (1986). El futuro de la democracia. México: Fondo de Cultura Económica. 
Böckenförde, E. W. (2000). Democracia y representación: crítica sobre la discusión actual sobre la democracia. En Estudios sobre el Estado de Derecho y la democracia (pp. 93-128). Madrid: Trotta.

Carré de Malberg, R. (2014). Consideraciones teóricas a propósito de la relación del referéndum con el parlamentarismo. Traducción de E. Guillén López. Revista de Derecho Constitucional Europeo, 21, 291-305.

Castellà Andreu, J. M. ${ }^{a}$ (2016). El referéndum sobre el brexit: una historia inacabada. Revista de Derecho Politico, 97, 297-334. Disponible en: https://doi.org/10.5944/ rdp.97.2016.17626.

Cuesta López, V. (2008). Participación directa e iniciativa legislativa del ciudadano en democracia constitucional. Pamplona: Aranzadi.

De Vega, P. (1985). La reforma constitucional y la problemática del poder constituyente. Madrid: Tecnos.

Donovan, T. (2014). Referendums and Initiatives in North America. En M. Qvortrup (ed.). Referendums around the World (pp. 122-161). New York: Palgrave Macmillan.

García López, E. (2012). Encuesta sobre el referéndum. Teoría y Realidad Constitucional, 30, 11-56.

Gerber, E. R. (1996). Legislative Response to the Threat of Popular Initiatives. American Journal of Political Science, 40 (1), 99-128. Disponible en: https://doi.org/10.2307/2111696.

Gonin, L. (2014). Swiss direct democracy in a globalized Word: a need for change? Comunicación defendida en The IXth Wordt Congress of Constitutional Law 2014, Oslo 16-20 de junio de 2014. Disponible en: https://bit.ly/2A2ObED.

Harvey, M. (2017). La experiencia escocesa en los referenda de devolución y secesión. Eunomía. Revista en Cultura de la Legalidad, 13, 61-79. Disponible en: https://doi. org/10.20318/eunomia.2017.3805.

Haskell, J. (2001). Direct Democracy or Representive Government? Dispelling the Populist Myth. Boulder, Colorado: Westwiew Press.

House of Lords Select Committee on the Constitution. (2010). Referendums in the United Kingdom, Twelfth Report of Session 2009-10. HL Paper 99, London. Disponible en: https://bit.ly/2mA6Fmd.

Josi, C. (2014). Direct democracy: what if there is a conflict between the will of the people and fundamental rights? A comparative analysis between Switzerland and California. Comunicación defendida en The IXth Wordt Congress of Constitutional Law 2014, Oslo 16-20 de junio de 2014. Disponible en: https://bit.ly/2A2ObED.

Kaufmann, B. y Waters, M. D. (eds.) (2004). Direct democracy in Europe. A comprehensive reference guide to the initiative and referendum process in Europe. Durham: Carolina Academic Press.

Kriesi, H. y Trechsel, A. (1996). Switzerland: the referendum and initiative as centerpiece of the political system. En M. Gallagher, M. y P. Uleri, P. V. (eds.). The Referendum Experience in Europe (pp. 185-208). London: Macmillan Press.

Laporta, F. J. (2016). Contra el referéndum. El País, 31-10-2016. Disponible en: https://bit. ly/2uWD2PH.

Lijphart, A. (1984). Democracies: Patterns of Majoritarian and Consensus Government in Twenty-One Countries. New Haven: Yale University Press. Disponible en: https://doi. org/10.2307/j.ctt1ww3w2t. 
Luciani, M. (2008). El referéndum, cuestiones teóricas y de la experiencia italiana. Revista Catalana de Dret Public, 37, 157-182.

Maravall, J. M. (2017). Populismos y representación. El País, 21-2-2017. Disponible en: https://bit.ly/2uXibvI.

Morel, L. (1993). Party Attitudes toward Referendums in Western Europe. West European Politics, 16 (3), 225-244. Disponible en: https://doi.org/10.1080/01402389308424972.

Nuss, P. (2000). Référendum et iniciative populaire en France? De l'illusion en général et de l'hypocrisie en particulier. Revue du Droit Public et de la Science Politique en France et à l'étranger, 5, 1441-1494.

Olivetti, M. (2007). Los referendos en serio: la experiencia italiana. Revista Jurídica de la Universidad Autónoma de Madrid, 15, 147-175.

Ovejero, F. (2016). ¿Democracias para niños? El Pais, 19-12-2016. Disponible en: https://bit. ly/2NCHHOS.

Penadés, A. (2016). Referéndums y democracia representativa. En F. González, G. Damiani y J. Fernández-Albertos (eds.). ¿Quién manda aquí? La crisis global de la democracia representativa (pp. 215-242). Barcelona: Debate.

- (2017). ¿A quién sirve el referéndum? El País, 27-5-2017. Disponible en: https://bit. ly/2mCB7fJ.

Pérez Sola, N. (2008). La institución del referéndum en Francia tras la reforma constitucional, una perspectiva comparada. Cuadernos de Derecho Público, 34-35, 117-146.

Qvortrup, M. (2002). A comparative study of referendums: government by the people. New York: Manchester University Press.

Requejo, P. (2013). Ciudadanos menores de edad. Revista Española de Derecho Constitucional, 99, 201-227.

Rolla, G. (2017). Las dinámicas entre el referéndum, las instituciones de democracia representativa y los partidos políticos. Consideraciones a la luz de la experiencia italiana. En P. Biglino (coord.). Partidos políticos y mediaciones de la democracia directa (pp. 201-236). Madrid: CEPC.

Ruini, M. (1953). Il referendum popolare e la revisione della Costituzione. Milano: Giuffrè.

Sáenz, E. (2016a). La regulación y la práctica del referéndum en Suiza: un análisis desde las críticas a la institución del referéndum. Revista de Estudios Políticos, 171, 71-104. Disponible en: https://doi.org/10.18042/cepc/rep.171.03.

- (2016b). La regulación del referéndum en el Derecho comparado: aportaciones para el debate en España. Revista Española de Derecho Constitucional, 108, 123-153.

Sáiz Arnáiz, A. (1992). El referéndum derogatorio en el ordenamiento italiano: entre las (incompletas) previsiones normativas y la (creativa) jurisprudencia constitucional. Revista Española de Derecho Constitucional, 36, 191-250.

Santamaría, J. (1972). Participación política y democracia directa. En Estudios de Ciencia Política y Sociología. Homenaje al Profesor Carlos Ollero (pp. 743-783). Madrid: Gráficas Carlavilla.

Sartori, G. (2007). ¿Qué es la democracia? México: Taurus.

Schneider, H. P. (1991). Soberano sin poder. Representación y participación del pueblo como problema de legitimación de la soberanía democrática. En Democracia y Constitución (pp. 249-272). Madrid: Centro de Estudios Constitucionales. 
Serdült, U. (2014). Referendums in Switzerland. En M. Qvortrup (ed.): Referendums around the World (pp. 65-121). New York: Palgrave Macmillan. Disponible en: https://doi. org/10.1057/9781137314703_4.

Soto Barrientos, F. (2013). El referéndum en Latinoamérica: un análisis desde el derecho comparado. Boletín Mexicano de Derecho Comparado, 136, 317-346. Disponible en: https:// doi.org/10.1016/S0041-8633(13)71129-3.

Svensson, P. (1996). Denmark: the referendum as minority protection. En M. Gallagher y P. V. Uleri (eds.). The Referendum Experience in Europe (pp. 33-51). London: Macmillan Press LTD. Disponible en: https://doi.org/10.1007/978-1-349-24796-7_3.

Tarr, G. A. (1998). Understanding State Constitutions. Princeton: Princeton University Press.

Tierney, S. (2012). Constitutional Referendums. The Theory and Practice of Republican Deliberation. Oxford: Oxford University Press. Disponible en: https://doi.org/10.1093/acprof:oso/9780199592791.001.0001.

Urquizu, I. (2014). ¿El referéndum como solución? Piedras de Papel, 22-9-2014. Disponible en: https://bit.ly/1sZky7b.

Weber, A. (1985). Direckte Demokratie im Landesverfassungsrecht. En Die Öffentliches Verwaltung (DöV), 38, 149-179. 